\title{
Cardiac MRI in Evaluation of Dilated Cardiomyopathy
}

\author{
Jyotsna Rani ${ }^{1}$ Narayanan Ramakrishna² \\ ${ }^{1}$ Department of Radiology \& Imageology, Nizams Institute of \\ Medical Sciences, Hyderabad, Telangana, India \\ ${ }^{2}$ Department of Radiology, Nizams Institute of Medical Sciences, \\ Hyderabad, Telangana, India \\ Ind J Car Dis Wom 2019;4:153-157
}

\begin{abstract}
Address for correspondence Jyotsna Rani, MD, Professor, Department of Radiology \& Imageology, Nizams Institute of Medical Sciences, Hyderabad, Telangana 500082, India (e-mail: yjyotsna@yahoo.com).
\end{abstract}

\begin{abstract}
Keywords

- dilated cardiomyopathy

- late gadolinium enhancement

- left ventricular dysfunction

Cardiac magnetic resonance imaging (MRI) plays an important role in the evaluation of dilated cardiomyopathy, and is the gold-standard technique in identifying the various etiological factors and differentiating one from the other. It not only helps in identifying the cause but also aids in monitoring the treatment response. The present article reviews the different MRI techniques available, recent advancements, and limitations in technology in the evaluation of patients with dilated cardiomyopathy in the present-day scenario.
\end{abstract}

\section{Introduction}

Dilated cardiomyopathy (DCM) is the cardiac muscle disorder occurs due to genetic, infective, inflammatory, or druginduced reasons, leading to left-ventricular dilation and systolic dysfunction..$^{1-5}$ It can have varied clinical manifestations from an asymptomatic state, heart failure to arrhythmias and death. ${ }^{6}$

Cardiac magnetic resonance imaging (CMRI) is currently considered the gold standard due to high temporal and excellent spatial resolution, enabling accurate assessment. The three-dimensional (3D) dataset available with MRI provides a more precise and reproducible method for quantifying ventricular volumes, mass, and function in patients with DCM. This technique provides insight into ventricular morphology, function, and myocardial tissue characterization. Tissue characterization with delayed contrast enhancement (CE) provides insight into the etiology of several myocardial diseases. It is also used to prognosticate the patient of DCM, as left-ventricular ejection fraction (LVEF) can be calculated accurately. ${ }^{7}$

Transthoracic two-dimensional (2D) echo (TTE; sometimes transesophageal echo [TEE], when there is a poor echo window) is helpful to know the severity of left-ventricular dysfunction (LVD) and degree of LV dilatation (end-diastolic diameter $>55 \mathrm{~mm}$ ), and may provide information to determine the cause of DCM. ${ }^{8}$ However with MRI, we can gather additional information, such as single-photon emission computed tomography myocardial perfusion scintigraphy (SPECT MPS), glucose metabolism on the F-18 fluorodeoxyglucose (18F-FDG) images, and cardiac CT rules out the ischemic component in DCM.

Delayed contrast material, enhanced cardiac magnetic resonance (MR) imaging, is used to detect both viability and myocardial infarction (MI). But its usage is increased in nonischemic cardiomyopathies, ${ }^{9}$ as the percentage of viable myocardium in this condition is also an important prognostic factor for mortality. In DCM, MRI provides a clue to take the biopsy for the diagnosis of secondary causes, when required. ${ }^{10}$

\section{MRI in DCM}

MRI is useful in DCM in multiple ways. It helps in differentiating ischemic from nonischemic cardiomyopathy and varieties of nonischemic forms, assessing both ventricular functions while determining CRT (cardiac resynchronize therapy), detecting thrombus, and prognosticating DCM.

\section{MR Technique}

There are changes in morphology in the form of dilatation of ventricular chambers and functional changes as well in a patient with dilated cardiomyopathy. Therefore, MRI
DOI https://doi.org/ $10.1055 / \mathrm{s}-0039-3401309$
(C2019 Women in Cardiology and Related Sciences
License terms

(ㅇ)(1) $\Theta$ 
protocols in the evaluation of dilated cardiomyopathy should be tailored to assess the morphology and functional status of the heart to arrive at a diagnosis. ${ }^{11,12}$

Cardiac MRI uses seven basic pulse sequences for the assessment of cardiovascular disease as mentioned below:

1. Black blood imaging for the assessment of cardiac morphology.

2. Bright blood imaging for creating cine and images of the heart.

3. Fat saturation imaging for the assessment of fatty infiltration of cardiac masses and myocardium.

4. Velocity encoding mapping for the measurement of blood flow.

5. Perfusion imaging with gadolinium for the evaluation of vascularity.

6. Inversion recovery late hyperenhancement (LHE) with gadolinium for the assessment of abnormal myocardial tissue composition 0.1 to $0.2 \mathrm{mmol} / \mathrm{kg}$ with a delay of 10 to 15 minutes which nulls the normal myocardial signal, so that pathological changes would be highlighted, and $^{7}$ angiography with gadolinium for the assessment of the vasculature. ${ }^{13}$

7. 3D whole-heart navigator-gated steady-state free precession (SSFP) for vascular anatomy, including coronary arteries, can be studied without contrast. ${ }^{14}$

\section{Basic Cardiac MRI}

The basic protocols include a four-chamber long axis, two-chamber vertical axis, and short-axis views using breath-hold cine SSFP sequences covering both ventricles.

In DCM, the static images by the spin-echo sequence, represented as black blood, are used to measure the dimensions of the LV. Cine loss by the gradient-echo is useful to quantify the severity of LV dysfunction. T1 or T2 contrast by preparation pulses are used for tissue characterization like edema, fibrosis, or different infiltrative disorders.

Fast and real-time sequences include fast low-angle shot, spiral, and echo-planar imaging.

MRI involves quantifying ventricular volumes, mass, and function in patients with DCM. Black and bright blood images provide information about the morphology of the heart. Gradient-echo sequences with an encoding of velocity are used for velocity and flow. DCM patients usually have heterogeneous end-diastolic LV wall thickness, and there is loss of the physiological gradient in systolic wall thickening between LV basal and apical segments. Fast gradient echo sequence can be used along with the T1-mapping technique to detect diffuse myocardial fibrosis. Fatty infiltration at particular chambers of the heart can be detected with fat saturation imaging to diagnose arrhythmogenic right ventricular dysplasia.

T1-weighted black blood is used for myocardial fat imaging, and T2-weighted short-tau inversion recovery (T2w-STIR) imaging using an ECG-gated triple inversion recovery (IR) technique is utilized to observe changes of tissue edema. The two- and four-chamber views are obtained for assessment of the entire heart. Abnormal myocardium appears bright in contrast to normal myocardium. The abnormal bright region can come due to edema, necrosis, fibrosis, or various infiltrates which expand the extracellular space of the myocardium. ${ }^{13,14}$ By T2-mapping technique, amount of intramyocardial iron deposition in hemochromatosis can be estimated.

Thrombus is suspected when there is a soft tissue intracavity mass, which does not enhance after contrast. and has variable signal intensity on either T1 or T2 images.

\section{Velocity Encoding Imaging}

To decrease the long-scan times for flow by MRI, a combination of phase contrast MRI fast sampling strategies, such as spiral or radial imaging, and other imaging strategies, such as balanced SSFP emerged. But, in velocity encoding, noise reduction along with increased spatial and/or temporal resolution is useful for the assessment of left ventricular performance (e.g., cardiac output) and regurgitation volumes. Secondary MRI in DCM can also be assessed by this method.

\section{MR Perfusion Images with Contrast}

Myocardial perfusion can be studied with contrast ( - Table 1).

\section{Patterns of Delayed Enhancement}

Gadolinium body of $0.2 \mathrm{mmol} / \mathrm{kg}$ is injected to look for the pattern of myocardial enhancement. Late gadolinium enhancement technique (LGE) acquire images 10 to 20 minutes after gadolinium injection. These images to be taken during breath-hold using a segmented $2 \mathrm{D}$ or $3 \mathrm{D}$

Table 1 Different MR techniques and information are provided

\begin{tabular}{|l|l|}
\hline MRI technique & Information \\
\hline $\begin{array}{l}\text { Dynamic first-pass perfusion } \\
\text { images }\end{array}$ & $\begin{array}{l}\text { Perfusion defects or microvas- } \\
\text { cular dysfunction }\end{array}$ \\
\hline $\begin{array}{l}\text { Delayed perfusion images } \\
\text { (IR-CE) }\end{array}$ & LGE-scar and fibrosis \\
\hline $\begin{array}{l}\text { T1-mapping techniques with } \\
\text { contrast }\end{array}$ & $\begin{array}{l}\text { Can measure ECV-a biomarker } \\
\text { of fibrosis. }\end{array}$ \\
\hline T2w-STIR imaging & $\begin{array}{l}\text { To detect the tissue edema, } \\
\text { which is a marker of active } \\
\text { inflammation }\end{array}$ \\
\hline $\begin{array}{l}\text { Cine SSFP or tagging tech- } \\
\text { niques }\end{array}$ & $\begin{array}{l}\text { For evaluation of ventricular } \\
\text { function and dyssynchrony }\end{array}$ \\
\hline PVR of MR & $\begin{array}{l}\text { Imaging datasets to simulate } \\
\text { endoscopic views of human } \\
\text { organ systems. }\end{array}$ \\
\hline Phase-contrast sequences & $\begin{array}{l}\text { For assessment of valvular } \\
\text { regurgitation and diastolic } \\
\text { function }\end{array}$ \\
\hline MR angiography & Vascular anatomy \\
\hline
\end{tabular}

Abbreviations: ECV, extracellular volume; IR-CE, inversion recovery contrast-enhanced; LGE, late gadolinium enhancement; MR, magnetic resonance; PVR, perspective volume rendering; SSFP. steady state free precession; T2w-STIR, T2-weighted short-tau inversion recovery. 
inversion recovery gradient-echo, with inversion time optimized to null myocardial signal intensity.

The following three different enhancement patterns can be recognized using LGE: subendocardial, transmural, or subepicardial. ${ }^{11}$ LGE located within the perfusion territory of an epicardial coronary artery can be classified as ischemic type, and abnormal enhancement not confined to a known vascular distribution is consistent with nonischemic causes ${ }^{15}$ (-Table 2).

\section{Ischemic Cardiomyopathy}

The primary role of cardiac MRI is to differentiate ischemic versus nonischemic dilated cardiomyopathy in the evaluation of various cardiomyopathies. Cine MRI images show regional wall motion abnormality of the affected myocardium. Normal myocardium does not show enhancement, whereas the infarcted area appears bright on late-enhancement images

Table 2 Distinguishing features of ischemic versus nonischemic cardiomyopathy on MRI

\begin{tabular}{|l|l|l|}
\hline $\begin{array}{l}\text { MR } \\
\text { technique }\end{array}$ & DCM nonischemic & $\begin{array}{l}\text { Ischemic } \\
\text { cardiomyopathy }\end{array}$ \\
\hline $\begin{array}{l}\text { Delayed-per- } \\
\text { fusion imag- } \\
\text { es-LGE }\end{array}$ & $\begin{array}{l}\text { 1. LGE-does not } \\
\text { correspond to } \\
\text { the particular } \\
\text { coronary territory } \\
\text { 2. Mid wall } \\
\text { enhancement }\end{array}$ & $\begin{array}{l}\text { 1. LGE-does cor- } \\
\text { respond to the } \\
\text { particular coronary } \\
\text { territory } \\
\text { 2. Subendocardial } \\
\text { or transmural } \\
\text { enhancement }\end{array}$ \\
\hline $\begin{array}{l}\text { First-pass } \\
\text { perfusion }\end{array}$ & $\begin{array}{l}\text { Normal or early in- } \\
\text { creased enhancement }\end{array}$ & $\begin{array}{l}\text { In acute phase-focal } \\
\text { perfusion defect }\end{array}$ \\
\hline $\begin{array}{l}\text { Cine MRI } \\
\text { images }\end{array}$ & $\begin{array}{l}\text { No RWMA of particu- } \\
\text { lar coronary territory }\end{array}$ & RWMA \\
\hline Plain MRI & $\begin{array}{l}\text { Marked dilated and } \\
\text { uniformly thinned out } \\
\text { ventricle }\end{array}$ & $\begin{array}{l}\text { The differential thick- } \\
\text { ness of the dilated } \\
\text { ventricle. }\end{array}$ \\
\hline
\end{tabular}

Abbreviations: DCM, dilated cardiomyopathy; LGE, late gadolinium enhancement; MRI, magnetic resonance imaging; RWMA, regional wall motion abnormalities.
(-Fig. 1). It can be focal to arterial distribution, and subendocardium is always involved. ${ }^{17}$

Both acute and chronic infarctions can enhance. In acute infarction, as there is myocardial cell membrane disruption, contrast enters into the cell. In chronic infarction, the contrast remains in the interstitium. ${ }^{18}$ Reimer and Jennings identified a pattern in late gadolinium enhancement of myocardium, that is, subendocardial extending to epicardium and transmural involvement resulting in wall motion abnormality.

\section{Nonischemic Dilated Cardiomyopathy}

Patients with idiopathic DCM either show no enhancement ( - Fig. 2) or linear mild myocardial enhancement ( - Fig. 3). However, McCrohon et al showed different patterns of enhancement. At $28 \%$, it was a linear mild myocardial pattern, subendocardial pattern at $13 \%$, and no enhancement at $59 \%{ }^{11}$ In asymptomatic patients or patients with mild symptoms, the presence of LGE was a predictor of adverse cardiac events.

\section{Viral Myocarditis}

Coxsackie virus B3 (CBV3) is considered the dominant viral etiological agent affecting the heart muscle - Fig. $3 .{ }^{19}$ Other frequently detected viral genomes are enterovirus, adenovirus, parvovirus B19 (PVB19), human herpes virus V6, and Epstein-Barr virus (EBV). ${ }^{20}$

Eighty percent of cases of myocarditis improve but $20 \%$ of cases may progress to DCM (33) due to a direct cytotoxic effect. Apart from reduced EF and regional wall motion abnormality, contrast-enhancement pattern, to some extent, helps in differentiating various viruses affecting the myocardium (-Table 3). T2-weighted image depicts edema and inflammation due to myocarditis in the myocardium. ${ }^{21}$

In acute myocarditis, there are myocardial segments with or without LGE. T2 relaxometry distinguishes between these myocardial segments, representing an inflammatory process. So, T2 relaxometry is useful to detect the global myocardial inflammatory process during the acute phase. This is
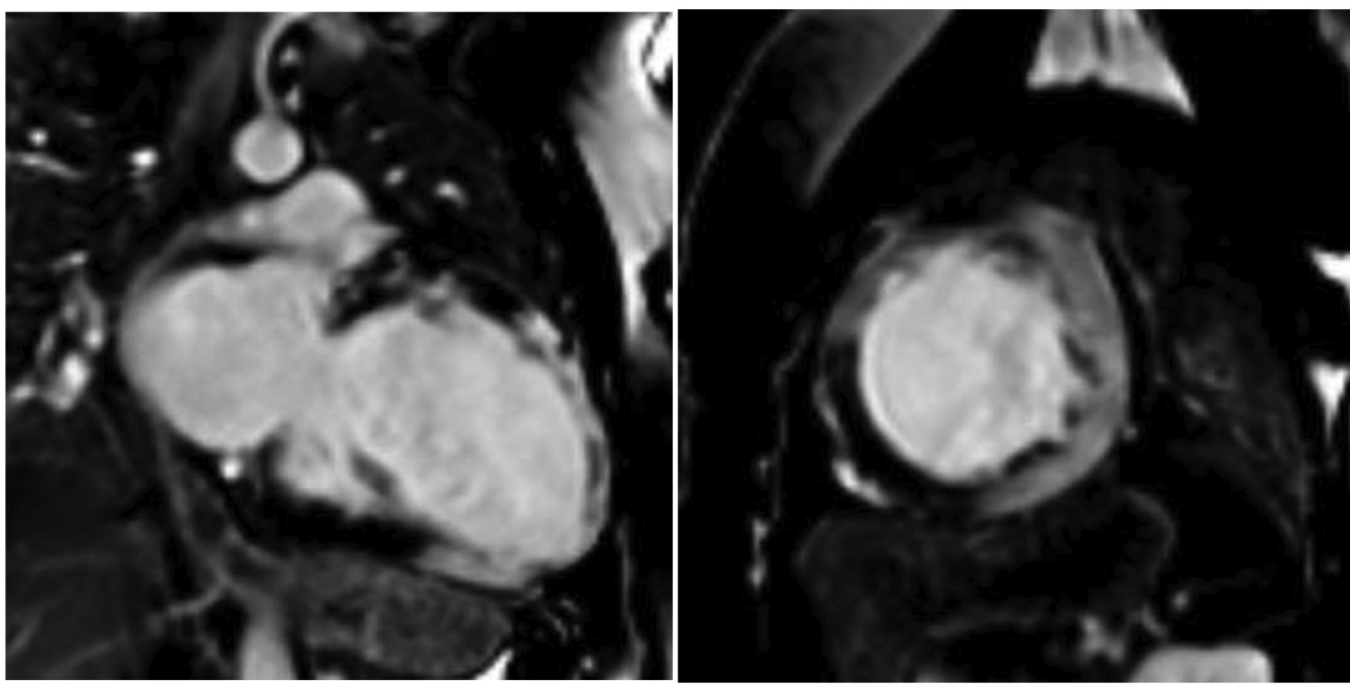

Fig. $145 \mathrm{Y} / \mathrm{F}$ with shortness of breath. Two-chamber and short-axis views are showing a dilated left ventricle, with transmural late gadolinium enhancement in anterior, lateral, and inferior walls, suggestive of infarction. Ejection fraction of $16 \%$. 

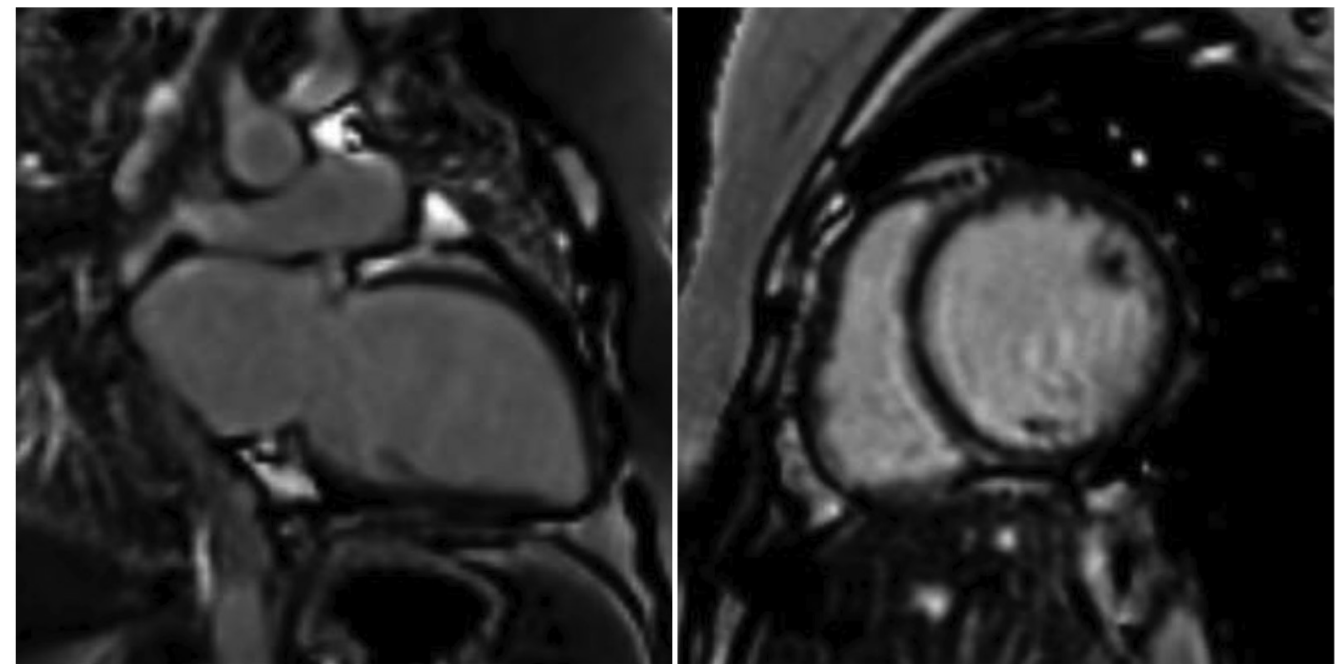

Fig. $220 \mathrm{Y} / \mathrm{F}$ with breathlessness. Two-chamber and short-axis views are showing a dilated left ventricle, with no late gadolinium enhancement in the myocardium to suggest fibrosis. The ejection fraction was $20 \%$.

Table 3 Type of contrast enhancement and related virus for myocarditis

\begin{tabular}{|l|l|}
\hline Area of contrast enhancement & Type of viral myocarditis \\
\hline Lateral free wall & PVB19 myocarditis \\
\hline Mid wall of the interventricular & 1. HHV6 myocarditis \\
septum & 2. Drug toxicity \\
& 3. Alcohol abuse ${ }^{11}$ \\
\hline
\end{tabular}

Abbreviations: HHV6, human herpes virus 6; PVB19, parovirus B19.

important as it is correlated with biochemical severity of myocarditis ${ }^{22}$ and planning for immunosuppressive therapy.

CE is useful to differentiate myocarditis from infarction. In addition, it gives a clue for the underlying type of virus which causes myocarditis ( - Fig. 3). ${ }^{23}$ The MRI findings during the acute phase of illness persist for a longer time. ${ }^{24}$ Clinical improvement in patients with myocarditis does not correlate with CMR findings and may persist for long in patients with myocarditis, as shown by Mahrholdt et al. ${ }^{23}$

\section{D MRI}

The 3D dataset available with MRI provides a more precise and reproducible method for quantifying ventricular volumes, mass, and function in patients with DCM.

\section{MR Spectroscopy}

This method assesses cardiac metabolism noninvasively. There is no need for any contrast for this study. Hydrogen spectroscopy provides information about myocardial cellular triglyceride levels. Phosphorus spectroscopy measures myocardial energetics. ${ }^{25}$

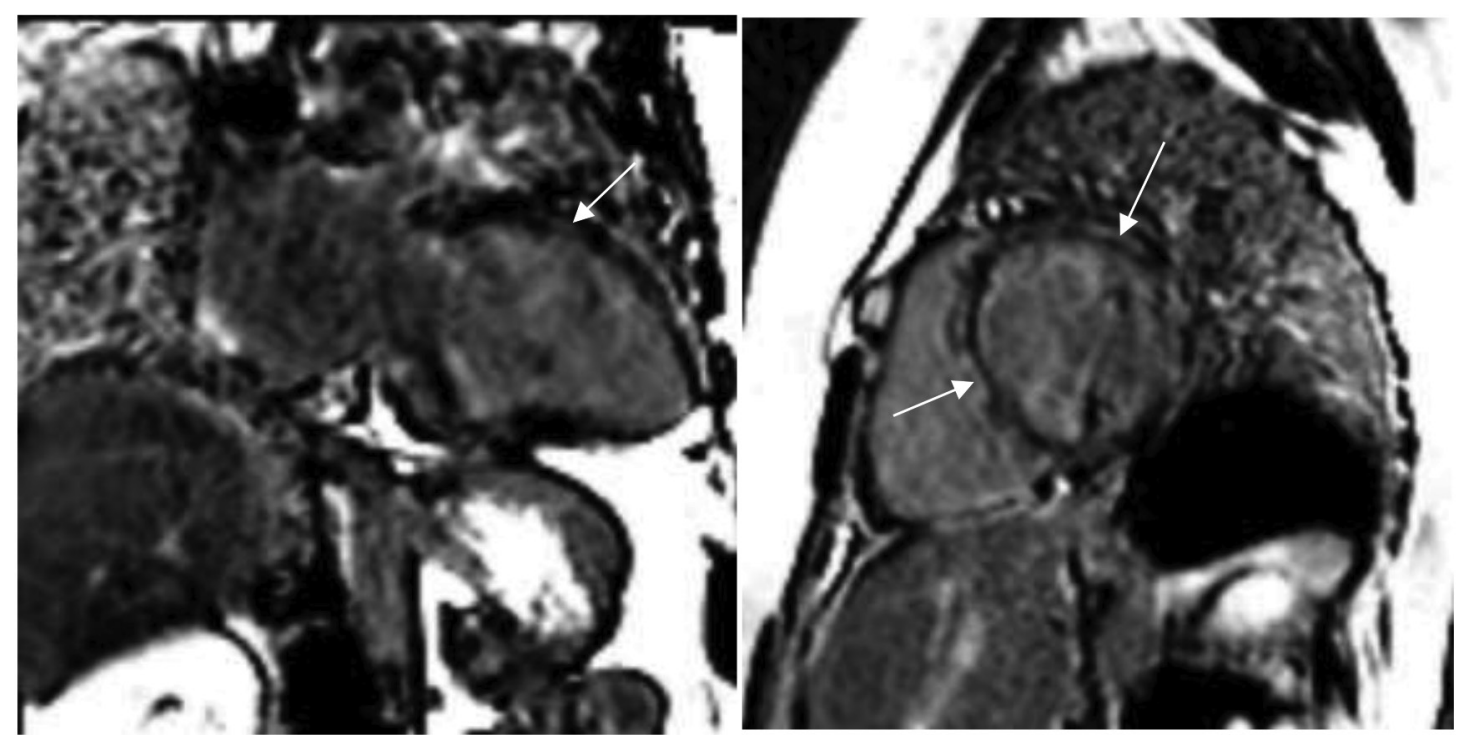

Fig. 329 Y/F with breathlessness. Two-chamber and short-axis views are showing mid myocardial (dashed arrows) and subepicardial (white arrows) late gadolinium enhancement in the anterior and apical wall, suggesting fibrosis. The ejection fraction was $26 \%$. 
Table 4 MRI finding in DCM for prognostification

\begin{tabular}{|l|l|}
\hline Finding & Implication \\
\hline $\begin{array}{l}\text { The presence of mid wall striae of tissue en- } \\
\text { hancement (may cause inducible ventricular } \\
\text { tachycardia) }\end{array}$ & $\begin{array}{l}\text { Candidate for } \\
\text { ICD }\end{array}$ \\
\hline Presence of LGE & $\begin{array}{l}\text { Predictor of } \\
\text { sudden cardiac } \\
\text { death }\end{array}$ \\
\hline
\end{tabular}

Abbreviations: DCM, dilated cardiomyopathy; ICD, implantable cardioverter defibrillator; LGE, late gadolinium enhancement; MRI, magnetic resonance imaging.

\section{Risk Stratification of Cardiomyopathy Using MRI}

As the distinction between idiopathic DCM and ischemic cardiomyopathy is possible by MRI, which has a different prognosis, MRI is used to risk stratify the cardiomyopathy (-Table 4).

\section{Limitations}

Like any other general contraindication to MRI study, patients with renal failure, pacemakers, etc., cannot undergo this examination. Although CMRI has several advantages over other diagnostic modalities in identifying the pathology, it experiences certain limitations in differentiating various nonischemic causes of dilated cardiomyopathy.

\section{Conclusion}

Cardiac MRI has evolved as an important diagnostic tool in the evaluation of patients with cardiomyopathy over the course of a decade. It is crucial to differentiate between ischemic and nonischemic DCMs and various conditions leading to nonischemic DCMs.

\section{Conflict of interest}

The author declares that there is no conflict of interest in publishing this article.

\section{Acknowledgment}

We thank our resident Sravan for helping us write this article.

\section{References}

1 Richardson P, McKenna W, Bristow M, et al. Report of the 1995 World Health Organization/International Society and Federation of Cardiology Task Force on the definition and classification of cardiomyopathies. Circulation 1996;93(5):841-842

2 Fatkin D, Otway R, Richmond Z. Genetics of dilated cardiomyopathy. Heart Fail Clin 2010;6(2):129-140

3 Weintraub RG, Semsarian C, Macdonald P. Dilated cardiomyopathy. Lancet 2017;390(10092):400-414

4 Lilly, LS. Pathophysiology of Heart Disease: A Collaborative Project of Medical Students And Faculty. Baltimore, MD Wolters Kluwer/Lippincott Williams \& Wilkins; 2011

5 Mitchell, RS, Kumar, V, Abbas, AK, Fausto, N. Robbins Basic Pathology. 8th ed. Philadelphia, PA: Elsevier
6 Olimulder MAGM, van Es J, Galjee MA. The importance of cardiac MRI as a diagnostic tool in viral myocarditis-induced cardiomyopathy. Neth Heart J 2009;17(12):481-486

7 W Gregory Hundley, David Bluemke, Jan G Bogaert, Matthias G Friedrich, Charles B Higgins, Mark A Lawson et al. CMR image acquisition protocols. Society for Cardiovascular Magnetic Resonance. 2008 June 3. doi:10.1186/1532-429X-11-5

8 Cummings KW, Bhalla S, Javidan-Nejad C. Bierhals AJ, Gutierrez FR, Woodard PK. A pattern-based approach to assessment of delayed enhancement in nonischemic cardiomyopathy at MR imaging. Radiographics 2009;29(1):89-103

9 Krombach GA, Hahn C, Tomars M, et al. Cardiac amyloidosis: MR imaging findings and T1 quantification, comparison with control subjects. J Magn Reson Imaging 2007;25(6):1283-1287

10 Thomas DE, Wheeler R, Yousef ZR, Masani ND. The role of echocardiography in guiding management in dilated cardiomyopathy. Eur J Echocardiogr 2009;10(8):iii15-iii21

11 McCrohon JA, Moon JCC, Prasad SK, et al. Differentiation of heart failure related to dilated cardiomyopathy and coronary artery disease using gadolinium-enhanced cardiovascular magnetic resonance. Circulation 2003;108(1):54-59

12 Nanjo S, Yoshikawa K, Harada M, et al. Correlation between left ventricular diastolic function and ejection fraction in dilated cardiomyopathy using magnetic resonance imaging with late gadolinium enhancement. Circ J 2009;73(10):1939-1944

13 Kalisz K, Rajiah P. Impact of cardiac magnetic resonance imaging in non-ischemic cardiomyopathies. World J Cardiol 2016;8(2):132-145

14 Belloni E, De Cobelli F, Esposito A, et al. MRI of cardiomyopathy. AJR Am J Roentgenol 2008;191(6):1702-1710

15 Mahrholdt H, Wagner A, Judd RM, Sechtem U, Kim RJ. Delayed enhancement cardiovascular magnetic resonance assessment of non-ischaemic cardiomyopathies. Eur Heart J 2005;26(15):1461-1474

16 Vignaux O. Cardiac sarcoidosis: spectrum of MRI features. AJR Am J Roentgenol 2005;184(1):249-254

17 De Smet K, Verdries D, Tanaka K, De Mey J, De Maeseneer M. MRI in the assessment of non ischemic myocardial diseases. Eur J Radiol 2012;81(7):1546-1548

18 Vigliano CA, Cabeza Meckert PM, Diez M, et al. Cardiomyocyte hypertrophy, oncosis, and autophagic vacuolization predict mortality in idiopathic dilated cardiomyopathy with advanced heart failure. J Am Coll Cardiol 2011;57(14):1523-1531

19 Esfandiarei M, McManus BM. Molecular biology and pathogenesis of viral myocarditis. Annu Rev Pathol 2008;3:127-155

20 Caforio AL, Calabrese F, Angelini A, et al. A prospective study of biopsy-proven myocarditis: prognostic relevance of clinical and aetiopathogenetic features at diagnosis. Eur Heart J 2007;28(11):1326-1333

21 Abdel-Aty H, Boyé P, Zagrosek A, et al. Diagnostic performance of cardiovascular magnetic resonance in patients with suspected acute myocarditis: comparison of different approaches. J Am Coll Cardiol 2005;45(11):1815-1822

22 Mayr A, Klug G, Feistritzer HJ, et al. Myocardial edema in acute myocarditis: relationship of T2 relaxometry and late enhancement burden by using dual-contrast turbo spin-echo MRI. Int J Cardiovasc Imaging 2017;33(11):1789-1794

23 Mahrholdt H, Wagner A, Deluigi CC, et al. Presentation, patterns of myocardial damage, and clinical course of viral myocarditis. Circulation 2006;114(15):1581-1590

24 Kearney MT, Cotton JM, Richardson PJ, Shah AM. Viral myocarditis and dilated cardiomyopathy: mechanisms, manifestations, and management. Postgrad Med J 2001;77(903):4-10

25 von Kienlin M. Cardiac 1H-MR spectroscopy. MAGMA 1998;6(2-3):107-108 